Ger J Exerc Sport Res 2020 · 50:463-469 https://doi.org/10.1007/s12662-020-00679-2 Received: 11 June 2020

Accepted: 12 September 2020

Published online: 9 October 2020

(c) The Author(s) 2020

\author{
Claudio R. Nigg ${ }^{1,2} \cdot$ Andreas Gessner $^{1}$ - Carina Nigg' ${ }^{1}$ - Marco Giurgiu' \\ Rainer Neumann ${ }^{1,3}$ \\ 'Institute of Sports and Sports Science, Karlsruhe Institute of Technology, Karlsruhe, Germany \\ ${ }^{2}$ Health Science Department, Institute of Sport Science, University of Bern, Bern, Switzerland \\ ${ }^{3}$ Institute of Movement and Sport, University of Education Karlsruhe, Karlsruhe, Germany
}

\title{
Demographic, physiological, psychological, and on-ice performance indicators predict plus/minus status of recreational ice hockey players across a season
}

\section{Introduction}

Sport game outcomes are often based on random events which makes it challenging to predict game outcomes (Boulier \& Stekler, 2003; Lames, 1998). To increase their chances of winning a game, a season or a tournament, ice hockey teams (and analysts) strive to find indicators and parameters predicting success in ice hockey and identifying key players contributing to the team's success (Lee, Kim, Chaeeun, Pathak, \& Moon, 2018). In competitive sports such as professional ice hockey, a good amount of research documents the performance indicators that influence match performance (Hvattum, 2019); however, due to limited resources (financial, staff, time), little is known about recreational athletes' performance indicators and metrics providing useful data about a player's contribution to the team's success.

A set of parameters to predict success in professional sports (e.g., National Hockey League [NHL], National Basketball League [NBA]) are performance indicators, including physiologi-

\section{Data Availability Statement}

Data of this project are available from the corresponding author. cal (Starkes, Helsen, \& Jack, 2001) and psychological characteristics (Sullivan \& Feltz, 2001). Janelle and Hillman (2003) suggest four domains being important to reach expert level: physiological, technical, cognitive (tactical/perceptual) and emotional. These domains which eventually lead to expert performance are all influenced by the psychological skills domain, with experts having superior abilities and skills in the domains relevant for the sport (Janelle \& Hillman, 2003).

In a professional ice hockey selection camp, selected players by expert coaches showed better physical and physiological parameters than nonselected players. The best predictors of success in the recruitment process were time to peak power and relative peak power as measured by the $30 \mathrm{~s}$ Wingate test, $\mathrm{VO} 2_{\max }$ and $30 \mathrm{~m}$ sprint forwards on ice (Roczniok et al., 2015). Fieldbased assessments seem to deliver more meaningful/predictive data compared to laboratory assessments (Henriksson, Vescovi, Fjellman-Wiklund, \& Gilenstam, 2016). Henriksson et al. (2016) identified single-leg standing long-jump as a valid method to gain knowledge about performance characteristics for skating among female ice hockey players.

Psychologically, achievement orientation may influence a player's on-ice performance. Achievement theory assumes that humans aim to demonstrate high abilities rather than low abilities (Roberts, Treasure, \& Conroy, 2007). One's abilities can be judged high or low referring to one's own performance (task orientation) or in relation to the performance of others (ego orientation; Nicholls, 1984). These different perceptions are part of Gill and Deeter's (1988) concept of sport orientation. While win orientation describes the athlete's orientation to judge his own performance only as success in the case of victory (ego orientation), goal orientation describes the athlete's orientation to excel his own performance, which means that athletes may also recognize failure as success as long as they improve their own performance (task orientation). Competitiveness is the third part of the orientation, referring to the athlete's perception of competition as enjoyment and challenge (Elbe, Meier, Wenhold, \& Beckmann, 2008). Task orientation has been positively associated with adaptive success factors, desirable behaviors, positive emotions, perceived competence and intrinsic motivation and negatively with 


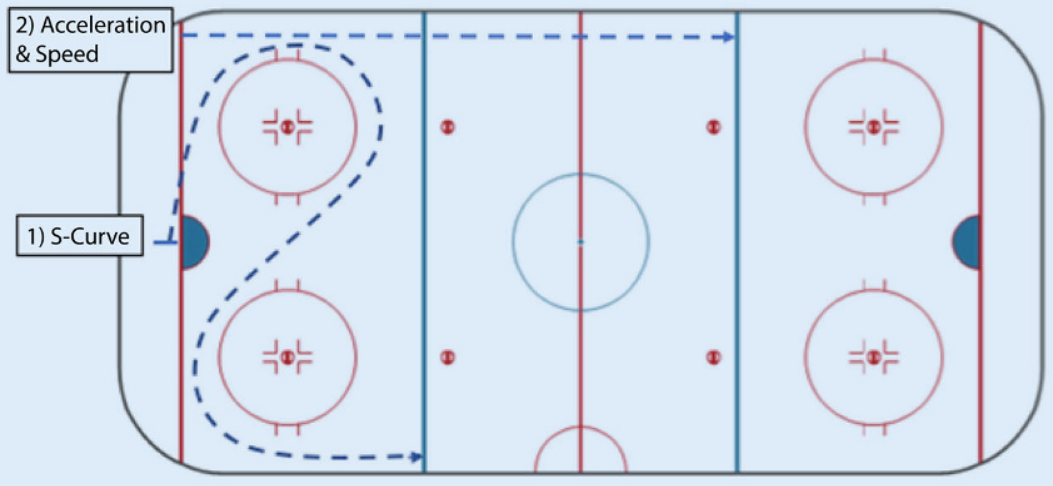

Fig. $1 \Delta$ Diagram of skating tests on an olympic-sized ice hockey rink

amotivation and maladaptive success factors (Lochbaum et al., 2016). In contrast, ego orientation has been positively associated with maladaptive success factors, undesirable behaviors and amotivation (Lochbaum et al., 2016). In team sports, task orientation is positively, and ego orientation negatively associated with the athletes' cooperation with teammates and coaches (Lameiras, Almeida, \& GarciaMas, 2014). Competitiveness has been associated with high performance (Hellandsig, 1998), reduced competitive anxiety in young adult athletes (Hellandsig, 1998) and sports motivation in professional women football players (Beaudoin, 2006). No studies could be found that have already explored those constructs in elite or recreational ice hockey players.

Cohesion, defined as a "dynamic process which is reflected in the tendency for a group to stick together and remain united in the pursuit of its goals and objectives" (Carron, 1982, p. 124), should also be considered in team sports. A meta-analysis showed that cohesion is strongly related to performance, with social cohesion being slightly stronger related than task cohesion (Carron, Colman, Wheeler, \& Stevens, 2002). Cohesion has already been explored in ice hockey, showing a positive relationship with performance (Salminen \& Luhtanen, 1998; Slater \& Sewell, 1994) and a positive relationship with a constructive conflict style in intrateam conflicts (Sullivan \& Feltz, 2001).

In addition to physiological and psychological performance indicators, there are many different types of game statistics quantifying a hockey player's team contribution. In ice hockey world championship games, parameters contributing to wins were goalkeeping and scoring efficiencies and the number of shots on goal (Lee \& Kim, 2018). Hockey performance statistics can be separated by team (e.g., goals for/against, shots on goal) or individual statistics (e.g., goals scored, plus/minus values). One potentially generalizable and useful metric is the (adjusted) plus-minus, which calculates how many goals a team scored and conceded for every player while s/he was playing on the ice (adjusted for special teams). In professional sports (NHL, NBA) the adjusted plus-minus (APM) is often used to estimate the player's impact on the game in even-strength situations (Macdonald, 2011). The APM incorporates both defensive and offensive aspects and is more accurate than other metrics that are commonly used (e.g. boxscore) (Macdonald, 2011). This is in line with previous studies which used plus/ minus values to evaluate individual performance across different sports (Macdonald, 2011; Okamoto, 2011; Kharrat, Peña, \& McHale, 2019). However, such metrics are generally only applied to elite hockey players/leagues to date (Macdonald, 2011). At the elite level, further adjusted versions of the APM have taken into account the quality of teammates and opposition players when calculating a plus-minus for a given player using regression models (Gramacy, Jensen, \& Taddy, 2013; Gramacy, Taddy, \& Tian,
2017; Thomas, Ventura, Jensen, \& Ma, 2013).

Even though this is a definite improvement and controls for important confounds, this kind of data is neither available nor collected for recreational players at this time. Recreational athletes participate in sport as a pastime, which may or may not be organized in league play. They also have less experience than professional hockey players, do not participate at the international level (Swann, Moran, \& Piggott, 2015), and most importantly do not participate for remuneration. Since amateur teams usually do not provide a lot of data, the plus-minus is a simple way to acquire potentially revealing data. The plus-minus for recreational athletes is appropriate for several reasons:

- To motivate the players: players can track their own performance or compare with their teammates' data across a season

- To focus on team and individual goal setting

- To acknowledge both offensive and defensive contributions

- To provide objective values making their on-field actions meaningful

Our goal was to investigate which performance parameters could deliver useful data explaining the plus-minus in recreational ice hockey players. This may motivate players to increase their commitment and participation, become more active during their leisure-time, and inform coaches where to focus to build confidence, cohesion, and cooperation.

\section{Methods}

\section{Participants}

The participants ( $n=20$ players, no goaltender; 1 female; mean age $=36.25 \pm$ 12.91 years; height $=178.85 \pm 8.64 \mathrm{~cm}$; weight $=81.36 \pm 12.89 \mathrm{~kg} ;$ mean years of ice hockey experience $=5.68 \pm 8.93$ ) were from one team playing in the 5 th level of the 9 level DPL (the German Players League), the largest recreational league across Germany with about 1100 players. Professional and former professional players are not allowed, there 
are two referees per game, slap shots are allowed, whereas bodychecks are not allowed and it is a self-organized league. The season for level 5 teams consisted of 8 games within the German state of Baden-Württemberg.

\section{Procedure}

Approval was obtained from the coach and the project was explained to the players upon which they provided informed consent. Anthropometrical data were collected right before and performance data was collected during a practice session after the 3rd game of the 8 game regular season and plus-minus were recorded after each game. Prior to this practice session every player took part in an online survey including demographics via SurveyMonkey.com. Some indicators were not assessed due to lack of resources (e.g., $\mathrm{VO} 2_{\max }$, and several fitness indicators). An ethical approval was not required as per the local legislation, due to this being an anonymous study containing anonymous data.

\section{Measures}

Demographics. Age, sex, hockey experience, and years on team were included.

Height and weight. Height and weight were measured without shoes and in light clothing. For height, the player had his back towards the stadiometer (Seca 216 Accu-Hite, seca gmbh \& co. kg., USA) standing tall on flat feet with head in the Frankfort plane with arms at the sides. A minimum of two height measurements were taken. If the values varied by $1 \mathrm{~mm}$ or less the average was recorded, if more than $1 \mathrm{~mm}$ an additional measurement was taken and the average of the three measurements was recorded. For weight, the player had to stand still with both feet on the scale (portable Health-o-Meter digital scale with a capacity of $170 \mathrm{~kg}$, Sunbeam Products Inc., USA). Two measurements of weight were taken. If the values varied by $0.1 \mathrm{~kg}$ or less the mean was recorded, if by more than $0.1 \mathrm{~kg}$ an additional measurement was taken and the average of the three measurements recorded.
Body fat. To determine the body fat a three site skinfold caliper (Lange Skinfold Caliper, Cambridge Scientific Industries Inc.) measurement was used (ACSM, 2013) measuring chest, back and suprailium for male and triceps, suprailium and thigh for the female was used. Every spot was measured two times and the average was taken. If the deviation of the two measures was more than $1 \mathrm{~mm}$ a third measurement executed and the average calculated.

Sport orientation and cohesion. The survey included the Sport Orientation Questionnaire (Elbe, Wenhold, \& Beckmann, 2008) which is the German translation of the original questionnaire by Gill \& Deeter (1988). The reliability and the accuracy of the translation have been confirmed (Elbe et al., 2008). The questionnaire consists of 25 items including three related subscales: level of competitiveness (13 items; current study Cronbach's alpha $(\alpha)=0.82)$, goal orientation ( 6 items; $\alpha=0.72$ ) and win orientation ( 6 items; $\alpha=0.68$ ). Response options ranged on a 5-point Likert scale from 1 ("Strongly disagree") to 5 ("Strongly agree"). For each scale, sum scores were used.

The MAKO-02 questionnaire investigates the social and task cohesion (Lau \& Stoll, 2002). It consists of 19 items aiming for social cohesion ( 9 items; $\alpha=0.72$ ) and task cohesion (10 items; $\alpha=0.83$ ). Validity and reliability have been confirmed (Lau \& Stoll, 2002). Response options ranged from 1 ("Strongly disagree") to 5 ("Strongly agree"). The score average was calculated for social and task cohesion respectively.

Muscular strength and endurance. We measured upper and lower body muscular strength and endurance based on the recommendation from Ransdell and Murray (2011) via the maximum repetitions during a $30 \mathrm{~s}$ interval for push-ups (upper body strength) and a separate $30 \mathrm{~s}$ interval for squats (lower body strength). One push-up repetition started with weight on hands and toes and straightened arms, went to the elbows being at $90^{\circ}$ and ended in the same straightened arm position. One squat
Ger J Exerc Sport Res 2020 · 50:463-469 https://doi.org/10.1007/s12662-020-00679-2 (c) The Author(s) 2020

\section{R. Nigg · A. Gessner · C. Nigg •} M. Giurgiu · R. Neumann

\section{Demographic, physiological, psychological, and on-ice performance indicators predict plus/minus status of recreational ice hockey players across a season}

\section{Abstract}

Little is known about physical, physiological, and psychological performance indicators predicting recreational athletes' performance. This information may motivate players to become more active and inform coaches where to focus to build confidence, cohesion, and cooperation. This study investigated which performance indicators were related to the plusminus statistic in German recreational ice hockey players ( $n=20$ players; 1 female; mean age $=36.25 \pm 12.91$ years;

height $=178.85 \pm 8.64 \mathrm{~cm}$; weight $=81.36 \pm 12.89 \mathrm{~kg}$; mean years of ice hockey experience $=5.68 \pm 8.93$ ) over a season. Anthropometrics, psychological and on-ice performance data were collected mid-season and plusminus were recorded after each game. Due to the small sample size, significance interpretations are not meaningful; therefore, Cohen's guidelines were used for $r=0.2$ (small), $r=0.5$ (medium) and $r=0.8$ (large). Medium size positive correlations of plus/minus were found for push-ups $(r=0.52)$ and squats $(r=0.37)$. Small positive correlations were found for shot speed $(r=0.33)$, competitiveness orientation $(r=0.28)$, and years on team $(r=0.23)$. Small negative correlations were found for win orientation $(r=-0.30)$, body mass index $(r=-0.28)$, task cohesion $(r=-0.24)$, and percent body fat $(r=-0.20)$. Some performance and psychological indicators are related to recreational ice hockey players' plus-minus statistic over a season. Coaches and players of recreational teams should focus on muscular strength and endurance, shooting speed, body composition, and enjoying the challenge of competition while lowering their win orientation.

Keywords

Amateur sports · Recreational games · Ice hockey $\cdot$ Athletic performance $\cdot$ Indicators 
Table 1 Demographics, physiological,

psychological, on-ice performance and plus-minus descriptives

\begin{tabular}{lll}
\hline Variable & Mean \pm SD \\
\hline Age & $36.25 \pm 12.91$ \\
\hline Experience (years) & $5.68 \pm 8.93$ \\
\hline On team (years) & $2.05 \pm 1.13$ \\
\hline Body fat (\%) & $18.43 \pm 5.75$ \\
\hline BMI (kg/m ${ }^{2}$ ) & $25.31 \pm 2.74$ \\
\hline Goal orientation & $25.6 \pm 3.05$ \\
\hline Win orientation & $21.45 \pm 2.87$ \\
\hline Comp orientation & $50.85 \pm 6.67$ \\
\hline Social cohesion & $5.79 \pm 0.70$ \\
\hline Task cohesion & $5.34 \pm 0.87$ \\
\hline Push-ups ( $n / 30 \mathrm{~s})$ & $28.53 \pm 8.46$ \\
\hline Squats ( $n / 30 \mathrm{~s})$ & $28.33 \pm 4.17$ \\
\hline S-Curve (s) & $9.90 \pm 0.48$ \\
\hline Acceleration (s) & $1.24 \pm 0.06$ \\
\hline Speed (s) & $3.93 \pm 0.22$ \\
\hline Shot accuracy $(/ 20)$ & $5.17 \pm 2.28$ \\
\hline Shot speed (km/h) & $66.77 \pm 14.85$ \\
\hline Plus/Minus & $0.05 \pm 3.02$ \\
\hline $\begin{array}{l}\text { BMI body mass index, SD standard devia- } \\
\text { tion, } n \text { number }\end{array}$ \\
\hline
\end{tabular}

repetition started with straightened legs with hands straight out front, lowered until the thigh was horizontal and ended in the straightened leg position.

Skating (- Fig. 1). 1) The first skating task was the agility cornering S-turn (Bracko, 2001; Farlinger, Kruisselbrink, \& Fowles, 2007; Nightingale, Miller, \& Turner, 2013). The start was behind the goal and the player with their hockey sticks had to circle to the right around the first face-off circle and then to the left around the second face-off circle and finish through the nearest blue line. 2) To measure acceleration and speed a straight line test was executed (Bracko, 2001; Farlinger et al., 2007; Nightingale et al., 2013). The players with their hockey sticks started at the goal line and finished at the far blue line. The acceleration was measured within the first 6.1 meters. The following $35 \mathrm{~m}$ measured the speed. In both conditions, validated timing lights with error correction processing (Smartspeed Pro, Fusion Sport, Coopers Plains, Australia) were used. For standardization every player started in the same position at a line
$50 \mathrm{~cm}$ behind the goal-line (the first pair of timing lights). The athletes executed the tests two times and averages were calculated.

Shooting accuracy and speed. 1) To monitor the accuracy there was a shooter tooter ( $72^{\prime \prime}$ Shooter Base Accushot) which had holes in each of the four corners (bottom left/right, top left/right). They had 5 shots at each corner and the goals scored were summed. 2) To measure shooting speed, we took the fastest out of three shots into the goal (without a target) with a speed measurement instrument set to $\mathrm{km} / \mathrm{h}$ (SpeedCheck, Outer Limits Sports; frequency set to $10.525 \mathrm{GHz}$ ).

Plus/minus. To be included in the analysis, each player had to play at least 2 games. This is to decrease the chance of an outlying performance and a player needs to participate in at least 2 games in order to be able to participate in the playoffs. After each game each player was asked for their plus/minus in the dressing room before he/she departed and this was validated with the coach's game notes.

\section{Results}

For the data analysis SPSS 25 (IBM, Armonk, NY, USA) was used. The independent variables were correlated (Pearson's r) with the dependent variable (plus/minus). Because of the small sample size, significance interpretations are not meaningful; therefore Cohen's (1988) guidelines were used for $r=0.2$ (small or weak), $\mathrm{r}=0.5$ (medium or moderate) and $r=0.8$ (large or strong). In terms of interpretation with small samples, correlations below 0.2 should not be considered practically meaningful relationships, whereas medium or higher correlations are indicative of practically meaningful relationships. The $p$-values are presented for comparison purposes with similar studies and for future metaanalyses. Analyses were rerun without the female resulting in similar conclusions; therefore data analyses are presented with all participants.
The mean and standard deviation (SD) of the study variables are presented in - Table 1.

The correlations among all the study variables are presented in $\bullet$ Table 2. For the purposes of this paper the focus is on the correlations of the study variables with the plus-minus statistic. The strongest positive correlations (medium size) were found with the muscular strength and endurance variables. Small positive correlations were found with shot speed, competitiveness orientation, and years on team. Small negative correlations were found with win orientation, body mass index (BMI), task cohesion, and percent body fat.

\section{Discussion}

This is one of the first studies to investigate psychological, muscular strength and endurance, and on-ice performance indicators related to outcome in recreational/ amateur ice hockey players. The muscular strength and endurance variables were most strongly positively associated with the plus-minus statistic over a season. Shooting speed, enjoying competition, and years on the team had a small positive relationship, whereas win orientation, task cohesion, BMI and body fat percent has a small negative relationship with the plus-minus statistic. Somewhat surprisingly, none of the skating variables were meaningfully related to plus-minus.

That muscular strength and endurance variables are most strongly related to the outcome replicates results of elite male (Peyer, Pivarnik, Eisenmann, \&Vorkapich, 2011) and female ice hockey players (Henriksson et al., 2016). Ice hockey requires strength in many facets (e.g. skating, accelerating and decelerating, balancing, stickhandling, defending the puck from opponents, and attempting to obtain the puck from opponents). That muscular strength and endurance was the strongest variable may be due to the skill level (recreational athletes) where some of the other specific on-ice skills like skating or shooting accuracy are not as developed as in elite athletes. Therefore, a recreational player may be well guided to ensure maintaining strength and possibly related fitness at 


\begin{tabular}{|c|c|c|c|c|c|c|c|c|c|c|c|c|c|c|c|c|c|}
\hline$\stackrel{\infty}{\rightleftharpoons}$ & $\begin{array}{ll}\simeq & n \\
0 & 0 \\
0\end{array}$ & $\tilde{n}$ & ஷุ & $\stackrel{\infty}{\stackrel{1}{i}}$ & $\bar{\sigma}$ & $\begin{array}{l}\text { m̃ } \\
\text { î }\end{array}$ & $\stackrel{\infty}{0}$ & $\stackrel{8}{0}$ & 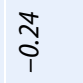 & గ్ర & $\hat{m}$ & $\tilde{O}$ & $\stackrel{1}{i}$ & ז. & ¿̊. & $\stackrel{m}{o}$ & - \\
\hline$\approx$ & 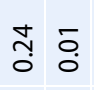 & 范 & 음 & $\stackrel{7}{0}$ & $\stackrel{\infty}{0}$ & $\begin{array}{c}m \\
m \\
i \\
i\end{array}$ & $\stackrel{8}{0}$ & $\begin{array}{l}\bar{\pi} \\
\bar{i}\end{array}$ & in & $\stackrel{\circ}{\circ}$ & $\begin{array}{l}\infty \\
0 \\
i \\
i\end{array}$ & $\frac{m}{0}$ & $\begin{array}{l}\overline{0} \\
0 \\
i\end{array}$ & $\overline{0}$ & $\begin{array}{c}\stackrel{0}{m} \\
\substack{i \\
i}\end{array}$ & - & I \\
\hline$\stackrel{\circ}{\circ}$ & 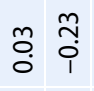 & స్రి & $\stackrel{n}{0}$ & $\frac{\circ}{\circ}$ & $\stackrel{J}{J}$ & ". & "艹 & $\stackrel{\text { ?n }}{\circ}$ & $\begin{array}{l}\text { no } \\
\text { ô }\end{array}$ & ָ̃ & $\frac{9}{0}$ & mi & 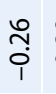 & 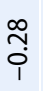 & - & 1 & 1 \\
\hline$\stackrel{n}{\simeq}$ & 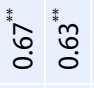 & స్ & $\stackrel{\hbar}{\hat{N}}$ & 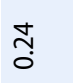 & స్̄ & 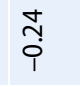 & : & "לn. & tit & $\begin{array}{l}\text { * } \\
\text { i } \\
\text { i }\end{array}$ & $\frac{a}{i}$ & $\frac{0}{4}$ & م. & - & 1 & 1 & I \\
\hline \pm & "స్ & 吕 & "in & $\stackrel{\substack{m \\
o}}{o}$ & г̄ & $\begin{array}{l}\stackrel{2}{0} \\
i \\
i\end{array}$ & $\begin{array}{l}\stackrel{0}{0} \\
\text { i }\end{array}$ & $\underset{0}{\tilde{O}}$ & ถู & $\begin{array}{l}\bar{n} \\
\bar{n} \\
i\end{array}$ & $\stackrel{m}{m}$ & "gọ. & - & 1 & 1 & 1 & 1 \\
\hline$\underline{m}$ & " & $\frac{0}{0}$ & "ِّ & 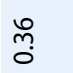 & fo & $\stackrel{\bar{i}}{\bar{i}}$ & $\begin{array}{l}n \\
\text { ñ } \\
\text { ô }\end{array}$ & $\stackrel{m}{o}$ & 广。 & $\stackrel{n}{m}$ & $\stackrel{\sim}{\stackrel{i}{i}}$ & - & 1 & 1 & 1 & 1 & 1 \\
\hline$\simeq$ & $\begin{array}{l}0 \\
0 \\
0 \\
0\end{array}$ & $\overline{ָ ্}$ & $\begin{array}{l}\text { Un } \\
0 \\
i\end{array}$ & $\begin{array}{l}\text { Oọ } \\
\text { i }\end{array}$ & $\hat{m}$ & $\bar{o}$ & ఫ̃ & $\bar{c}$ & ָָ & in & - & 1 & 1 & 1 & 1 & 1 & 1 \\
\hline$=$ & $\begin{array}{cc}\bar{m} \\
\bar{m} \\
i \\
i\end{array}$ & $\begin{array}{l}0 \\
0 \\
\text { iे }\end{array}$ & 色 & 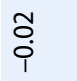 & $\stackrel{\text { ֻ }}{\circ}$ & $\frac{0}{i}$ & 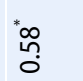 & 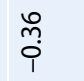 & 㐫 & - & 1 & 1 & 1 & 1 & 1 & 1 & 1 \\
\hline 우 & $\bar{m} \hat{o}$ & ஜ̊. & "ה & $\overline{\tilde{o}}$ & @̊ & ঃ. & $\begin{array}{c}\text { } \\
\stackrel{n}{1} \\
i\end{array}$ & fั & - & 1 & 1 & 1 & 1 & 1 & I & 1 & 1 \\
\hline$a$ & 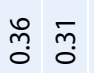 & $\underset{0}{\stackrel{J}{0}}$ & "0. & $\overline{ָ ্}$ & $\overline{0}$ & $\stackrel{\infty}{0}$ & 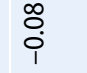 & - & 1 & 1 & 1 & 1 & 1 & 1 & 1 & 1 & 1 \\
\hline$\infty$ & 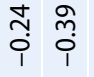 & $\underset{0}{\mathbb{O}}$ & 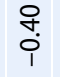 & $\begin{array}{l}n \\
0 \\
i \\
i\end{array}$ & 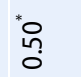 & "n & - & 1 & 1 & 1 & 1 & 1 & 1 & 1 & 1 & 1 & 1 \\
\hline N & $\ddot{m}_{0}^{n} \overline{\tilde{m}}$ & $\frac{m}{0}$ & $\frac{\circ}{0}$ & $\stackrel{\infty}{\sim}$ & $\stackrel{\substack{n \\
\tilde{o}}}{o}$ & - & 1 & 1 & 1 & 1 & 1 & 1 & 1 & 1 & 1 & 1 & 1 \\
\hline 0 & 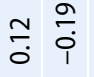 & $\begin{array}{l}\infty \\
0 \\
i\end{array}$ & $\frac{0}{i}$ & $\stackrel{0}{0}$ & - & 1 & 1 & 1 & 1 & 1 & 1 & 1 & 1 & 1 & 1 & 1 & 1 \\
\hline in & ֻ̃. & $\frac{0}{0}$ & I̊. & - & 1 & 1 & 1 & 1 & 1 & 1 & 1 & 1 & I & 1 & 1 & 1 & 1 \\
\hline$\sigma$ & 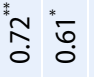 & $\frac{\infty}{0}$ & - & 1 & I & 1 & 1 & 1 & 1 & 1 & 1 & 1 & 1 & 1 & 1 & 1 & I \\
\hline$m$ & ס্ं & - & 1 & 1 & 1 & 1 & 1 & 1 & 1 & 1 & 1 & 1 & 1 & 1 & 1 & I & 1 \\
\hline$N$ & ¿. - & 1 & 1 & 1 & 1 & 1 & 1 & 1 & 1 & 1 & 1 & 1 & 1 & 1 & 1 & 1 & I \\
\hline$\tau$ & -1 & 1 & 1 & 1 & 1 & 1 & 1 & 1 & 1 & 1 & 1 & 1 & 1 & 1 & 1 & 1 & 1 \\
\hline & & 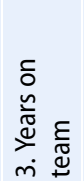 & $\begin{array}{l}\stackrel{5}{\frac{\pi}{0}} \\
\text { के } \\
\infty \\
\dot{\sigma}\end{array}$ & 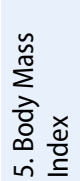 & 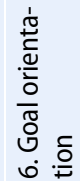 & 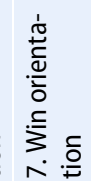 & 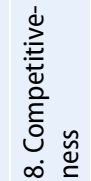 & 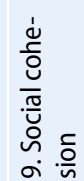 & 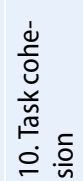 & $\begin{array}{l}\frac{u}{3} \\
\frac{1}{1} \\
\frac{n}{3} \\
0 \\
\dot{0}\end{array}$ & $\begin{array}{l}\frac{n}{\pi} \\
\frac{\pi}{0} \\
\tilde{U} \\
\stackrel{\sim}{\simeq}\end{array}$ & 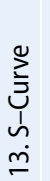 & 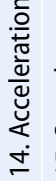 & 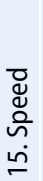 & & 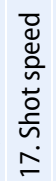 & 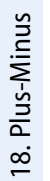 \\
\hline
\end{tabular}


the amateur level. Related, but perhaps not surprising, are the findings that higher BMI and body fat percent may be related to lower performance outcomes. This has also been found in elite ice hockey players (Montgomery, 1988), although not always significant (Peyer et al., 2011) and may be an indicator of overall fitness. There may be differences in recreational compared to professional ice-hockey players as overall preseason player size and anaerobic and aerobic fitness parameters of a professional NHL ice-hockey team was not related to team success over a 26-year period (Quinney et al., 2008).

The psychological results also replicate those found in elite athletes. Our study indicates that enjoying the challenge of competition is beneficial for recreational athletes as in elite athletes (Hellandsig, 1998). In contrast, win (ego) orientation and task cohesion may be detrimental to performance in our recreational ice hockey players as in elite athletes (Lameiras et al., 2014; Lochbaum et al., 2016). Win orientation and task cohesion may be detrimental if the players redirect focus on specific tasks (e.g., focus on forechecking or scoring goals) to the detriment of overall game performance. This underlines the importance of adopting a team atmosphere of enjoying competition and decrease focus of win-at-allcosts (ego) orientations across skill levels.

That acceleration, speed, or curve skating was not related to plus/minus rating replicates results with elite $\mathrm{Na}$ tional Collegiate Athletic Association division I ice hockey players (Peyer et al., 2011) and may be due to a couple of reasons. The small dispersion of the participants' performance (the standard deviation is less than $5 \%$ of the mean) indicates that the players were very similar in skating ability; thus this factor did not differentiate the players in terms of skill. Statistically, the relatively small dispersion limits the indicators' ability to explain outcome variability. There may be other not-tested skating skills that should be included such as starting and stopping, backwards skating, or repeated skating performance which may be more related to game performance. Stanula, Roczniok, Gabryś, Szmatlan-Gabryś, \&
Ozimek (2018) did find that a fatigue index calculated from the repeated-skate sprint test was significantly related to the plus/minus rating with elite Polish men's national ice hockey players participating in the U18 Ice Hockey World Championship.

This study added to the literature in that it included psychological, muscular strength and endurance, and on-ice performance indicators, tracked outcomes across an entire season, and addressed recreational athletes. However, some limitations need to be considered when interpreting our results. Some potentially important indicators were not assessed (e.g., $\mathrm{VO} 2_{\max }$, and several fitness indicators) limiting the comprehensiveness of the variables included. The study focused on one team of one skill level in one German recreational league limiting generalizability. Assessing the performance and psychological indicators during the season midpoint does not allow investigating the indicator changes occurring during the season on outcomes. There was no external recorder of the plus-minus statistics; however this is not deemed a serious limitation as the players/linemates were each other's validity checks after each game decreasing the chance of anyone's biased reporting. Finally, the small sample sizes does not allow for subgroup (e.g., position) analyses.

The limitations notwithstanding, this study revealed that some performance and psychological indicators are related to recreational ice hockey players' plus-minus ratings over a season. Thus, coaches and players of recreational teams should focus on muscular strength and endurance, shooting speed, body composition, and enjoying the challenge of competition while lowering their win orientation. Future directions include larger sample sizes of different amateur teams across skill levels and leagues to replicate and increase generalizability, including a more comprehensive set of indicators, off-ice fitness indicators, and experimental studies based on these results to improve the meaningfulness of the indicators in order to improve performance in recreational ice hockey players.

\section{Corresponding address}

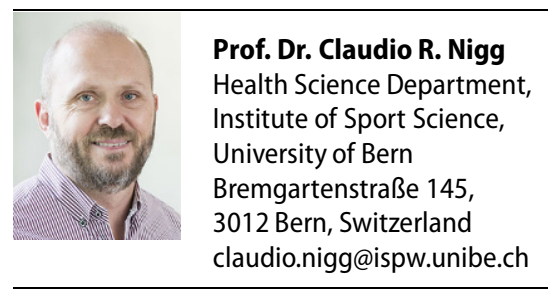

Acknowledgements. The authors would like to acknowledge the input from the coach and players of the participating team.

Funding. Open access funding provided by University of Bern

\section{Compliance with ethical guidelines}

Conflict of interest. C. R. Nigg, A. Gessner, C. Nigg, M. Giurgiu and R. Neumann declare that they have no competing interests.

For this article, an ethical approval was not required as per the local legislation, due to this being an anonymous study containing anonymous data. This study was performed in accordance with the ethical standards indicated in each case.

Open Access. This article is licensed under a Creative Commons Attribution 4.0 International License, which permits use, sharing, adaptation, distribution and reproduction in any medium or format, as long as you give appropriate credit to the original author(s) and the source, provide a link to the Creative Commons licence, and indicate if changes were made. The images or other third party material in this article are included in the article's Creative Commons licence, unless indicated otherwise in a credit line to the material. If material is not included in the article's Creative Commons licence and your intended use is not permitted by statutory regulation or exceeds the permitted use, you will need to obtain permission directly from the copyright holder. To view a copy of this licence, visit http://creativecommons.org/licenses/by/4.0/.

\section{References}

American College of Sports Medicine (2013). ACSM's guidelines for exercise testing and prescription. Philadelphia: Lippincott Williams \& Wilkins.

Beaudoin, C. M. (2006). Competitive orientations and sport motivation of professional women football players: an Internet survey. Journal of Sport Behavior, 29(3), 201-212.

Boulier, B. L., \& Stekler, H. O. (2003). Predicting the outcomes of National Football League games. International Journal of Forecasting, 19, 157-270.

Bracko, M. R. (2001). On-ice performance characteristics of elite and non-elite women's ice hockey players. Journal of Strength and Conditioning Research, 15, 42-47.

Carron, A. V. (1982). Cohesiveness in sport groups: interpretations and considerations. Journal of Sport Psychology, 4(2), 123-138. https://doi.org/ 10.1123/jsp.4.2.123. 
Carron, A. V., Colman, M. M., Wheeler, J., \& Stevens, D. (2002). Cohesion and performance in sport: a meta analysis. Journal of Sport and Exercise Psychology, 24(2), 168-188. https://doi.org/10. 1123/jsep.24.2.168.

Cohen, J. (1988). Statistical power analysis for the behavioral sciences (2nd edn.). Hillsdale: Erlbaum.

Elbe, A.-M., Meier, C., Wenhold, F., \& Beckmann, J. (2008). Informationen zum deutschen Sport Orientation Questionnaire auf dem Internetportal Sportpsychologie des BISp [Information about the German sport orientation questionnaire of the BISp Internet platform sports psychology]. www. bisp.de

Elbe, A.-M., Wenhold, F., \& Beckmann, J. (2008). SOQ: Fragebogen zur Erfassung der Leistungsorientierung im Sport [SOQ: Questionnaire for the sports orientation assessement]. www.bisp.de

Farlinger, C.M., Kruisselbrink, L.D., \& Fowles, J.R. (2007). Relationships to skating performance in competitive hockey players. Journal of Strength and Conditioning Research, 21,915-922.

Gill, D.L., \& Deeter, T.E. (1988). Development of the sport orientation questionnaire. Research Quarterly for Exercise and Sport, 59, 191-202.

Gramacy, R., Jensen, S., \& Taddy, M. (2013). Estimating player contribution in hockey with regularized logistic regression. Journal of Quantitative Analysis in Sports, 9, 97-111. https://doi.org/10. 1515/jqas-2012-0001.

Gramacy, R., Taddy, M., \& Tian, S. (2017). Hockey performance via regularized logistic regression. In J. Albert, M. Glickman, T. Swartz \& R. Koning (Eds.), Handbook of statistical methods and analyses in sports (pp. 287-306). Boca Raton: CRCPress.

Hellandsig, E. T. (1998). Motivational predictors of high performance and discontinuation in different types of sports among talented teenage athletes. International Journal of Sport Psychology, 29(1), 27-44.

Henriksson, T., Vescovi, J.D., Fjellman-Wiklund, A. \& Gilenstam, K. (2016). Laboratory- and field-based testing as predictors of skating performance in competitive-level female ice hockey. Open Access Journal of Sports Medicine, 7, 81-88. https://doi.org/10.2147/OAJSM. S109124.

Hvattum, L. M. (2019). A comprehensive review of plusminus ratings for evaluating individual players in team sports. International Journal of Computer Science in Sport, 1, 1-23.

Janelle, C. M., \& Hillman, C. H. (2003). Expert performance in sport: current perspectives and critical issues. In J. L. Starkes \& K. A. Ericsson (Eds.), Expert performance in sports: advances in research on sport expertise (pp. 19-47). Champaign: Human Kinetics.

Kharrat, T., Peña, J. L., \& McHale, I. G. (2019). Plus-minus player ratings for soccer. European Journal of Operational Research. https://doi.org/10.1016/j. ejor.2019.11.026.

Lameiras, J., Almeida, P. L., \& Garcia-Mas, A. (2014). Relationships between cooperation and goal orientation among male professional and semiprofessional team athletes. Perceptual and Motor Skills, 119(3), 851-860. https://doi.org/10.2466/ 25.PMS.119c32z4.

Lames, M. (1998). Leistungsfähigkeit, Leistung und Erfolg - ein Beitrag zur Theorie der Sportspiele [Perfomance ability, perfomance and success-A contribution to the theory of sportgame performance ability]. Sportwissenschaft, 28, 137-152.

Lau, A., \& Stoll, O. (2002). Validität und Reliabilität des Fragebogens zur Mannschaftskohäsion von Sportspielmannschaften [Validity and reliability of a questionnaire for team cohesion in team play sports] (MAKO-02). In S. Schulz (Ed.), Bericht über den 43. Kongress der Deutschen Gesellschaft für Psychologie in Berlin (p. 374). Lengerich: Papst Science.

Lee, J., Kim, H., Chaeeun, K., Pathak, P., \& Moon, J. (2018) Factors contributing to winning in ice hockey: analysis of 2017 ice hockey world championship. The Korean Journal of Physical Education, 57 387-394. https://doi.org/10.23949/KJPE.2018. 07.57.4.27.

Lochbaum, M., Zazo, R., Cetinkalp, Z. K., Wright, T., Graham, K. A., \& Konttinen, N. (2016). A metaanalytic review of achievement goal orientation correlation in competitive sport: a follow-up to Lochbaum et al. (2016). Kinesiology, 48(2), 159-173. https://doi.org/10.26582/k.48.2.15.

Macdonald, B. (2011). A regression-based adjusted plus-minus statistic for NHL players. Journal of Quantitative Analysis in Sports. https://doi.org/ 10.2202/1559-0410.1284.

Montgomery, D. L. (1988). Physiology of ice hockey. Sports Medicine, 5, 99-126.

Nicholls, J.G. (1984). Achievement motivation: conceptions of ability, subjective experience, task choice, and performance. Psychological Review, 91(3), 328

Nightingale, S.C., Miller, S., \& Turner, A. (2013). The usefulness and reliability of fitness testing protocols for ice hockey players. A literature review. Journal of Strength and Conditioning Research, 27, 1742-1748.

Okamoto, D.M. (2011). Stratified odds ratios for evaluating NBA players based on their plus/ minus statistics. Journal of Quantitative Analysis in Sports. https://doi.org/10.2202/1559-0410. 1320.

Peyer, K. L., Pivarnik, J. M., Eisenmann, J. C., \& Vorkapich, M. (2011). Physiologicalcharacteristics of National Collegiate Athletic Association Division I ice hockey players and their relation to game performance. Journal of Strength and Conditioning Research, 25, 1183-1192.

Quinney, H. A., Dewart, R., Game, A., Snydmiller, G., Warburton, D., \& Bell, G. (2008). A 26 year physiological description of a National Hockey League team. Applied Physiology, Nutrition, and Metabolism, 33, 753-760. https://doi.org/10. 1139/H08-051.

Ransdell, L. B., \& Murray, T. (2011). A physical profile of elite female ice hockey players from the USA Journal of Strength and Conditioning Research, 25, 2358-2363.

Roberts, G. C., Treasure, D.C., \& Conroy, D.E. (2007). Understanding the dynamics of motivation in sport and physical activity: an achievement goal interpretation. In Handbook of sport psychology (3rd edn., pp. 3-30). Hoboken: John Wiley \& Sons Inc.

Roczniok, R., Stanula, A., Maszczyk, A., Mostowik, A., Kowalczyk, M., Fidos-Czuba, O., \&Zajac, A. (2015) Physiological, physical and on-ice performance criteria for selection of elite ice hockey teams. Biology of Sport, 33(1), 43-48. https://doi.org/ 10.5604/20831862.1180175.

Salminen, S., \& Luhtanen, P. (1998). Cohesion predicts success in junior ice hockey. Perceptual and Motor Skills, 87(2), 649-650. https://doi.org/10. 2466/pms.1998.87.2.649.
Slater, M. R., \& Sewell, D. F. (1994). An examination of the cohesion-performance relationship in university hockey teams. Journal of Sports Sciences, 12(5), 423-431. https://doi.org/10. 1080/02640419408732192.

Stanula, A.J., Roczniok, R.K., Gabryś, T.T., Szmatlan-Gabryś, U. B., \& Ozimek, M. J. (2018). Relationships of physical fitness test results and player performance indicators in national-level ice hockey players. Society. Integration. Education. Proceedings of the International Scientific Conference, Rēzeknes Tehnologiju akadēmija. V ol. IV (pp. 264-273)

Starkes, J. L., Helsen, W. F., \& Jack, R. (2001). Expert performance in sport and dance. In R. N. Singer, H. A. Hausenblas \& C. M. Janelle (Eds.), Handbook of Sport Psychology (pp. 174-201). Hoboken: John Wiley \& Sons Inc..

Sullivan, P. J., \& Feltz, D.L. (2001). The relationship between intrateam conflict and cohesion within hockey teams. Small Group Research, 32(3), 342-355.

Swann, C., Moran, A., \& Piggott, D. (2015). Defining elite athletes: issues in the study of expert performance in sport psychology. Psychology of Sport and Exercise. https://doi.org/10.1016/j. psychsport.2014.07.004

Thomas, A., Ventura, S., Jensen, S., \& Ma, S. (2013). Competing process hazard function models for player ratings in ice hockey. The Annals of Applied Statistics, 7, 1497-1524. https://doi.org/ 10.1214/13-AOAS646. 